OPEN ACCESS

Edited by: Osman Titrek

Sakarya University, Turkey

Reviewed by:

Matthias Weiss,

Ruhr University Bochum, Germany

Qingbai Zhao,

Central China Normal University,

China

${ }^{*}$ Correspondence:

Shudi Liao

shudiliao@hubu.edu.cn

Specialty section:

This article was submitted to

Organizational Psychology,

a section of the journal

Frontiers in Psychology

Received: 04 August 2021 Accepted: 15 November 2021 Published: 16 December 2021

Citation:

Zhang W, Liao S, Liao J and

Zheng Q (2021) Paradoxical Leadership and Employee Task Performance: A Sense-Making

Perspective.

Front. Psychol. 12:753116 doi: 10.3389/fpsyg.2021.753116

\section{Paradoxical Leadership and Employee Task Performance: A Sense-Making Perspective}

\author{
Wei Zhang ${ }^{1}$, Shudi Liao ${ }^{2,3 *}$, Jianqiao Liao' ${ }^{1}$ and Quanfang Zheng ${ }^{4}$ \\ ${ }^{1}$ School of Management, Huazhong University of Science and Technology, Wuhan, China, ${ }^{2}$ Business School, Hubei \\ University, Wuhan, China, ${ }^{3}$ Hubei Center for Studies of Human Capital Development Strategy and Policy, Key Research \\ Base of Humanities and Social Science of Hubei Province, Wuhan, China, ${ }^{4}$ School of Business Administration, Zhongnan \\ University of Economics and Law, Wuhan, China
}

Paradoxical leadership has received increasing research attention in recent years. Yet, questions remain as to why and when paradoxical leadership is effective in promoting employee work outcomes. Drawing upon the sense-making perspective, we propose that paradoxical leadership enhances employee task performance by increasing employees' adaptability, and paradoxical leadership is more effective when employees have higher levels of Zhong Yong thinking and organizational identification. To test our hypotheses, we conducted a multi-source and multi-wave survey study among 235 employees and their supervisors in southern China. The results of the regression analyses fully support our hypotheses. In general, our findings shed light on the underlying mechanisms, as well as the boundary conditions, of the effect of paradoxical leadership. The theoretical and practical implications of these findings are discussed.

Keywords: paradoxical leadership, sense-making, adaptability, task performance, Zhong Yong thinking, organizational identification

\section{INTRODUCTION}

The concept of paradoxical leadership, defined by Zhang et al. (2015), refers to leaders' seemingly competing yet interrelated behaviors to meet competing workplace demands simultaneously and over time. This kind of leadership has been one of the most popular research topics in the past few years. Paradoxical leadership attracts such attention because of its advantages in dealing with organizational paradoxes. Evidence has shown that paradoxical leadership is associated with better employee and team performance, such as work role performance, creativity, and innovative behaviors (Zhang et al., 2015, 2021; Shao et al., 2019; Yang et al., 2021).

Employee task performance-reflects to what extent employees achieve the officially required outcomes and behaviors that directly serve the organization's goals (Motowidlo and Van Scotter, 1994) - is crucial for organizational survival and growth in a complicated and conflicted environment. The competitive pressures which extend from this environment accentuate the importance of achieving superior task performance. Therefore, how to promote individuals' task performance has become an increasing concern for paradoxical leaders. Many mechanisms have been proposed to explain the positive effects of paradoxical leadership on employees' task performance, but few studies have been focused on the explanatory mechanisms from the lens of followers' own interpretations of leader behaviors. The success of a paradoxical leader's competing value framework is highly dependent on employees' own interpretations. For example, when tensions from conflicting or competing demands become salient, employees may respond positively 
or negatively. A negative reaction involves defensive mechanisms such as denial and repression (Vince and Broussine, 1996) that can lead to potentially detrimental outcomes (Lewis, 2000). A positive reaction focuses on opportunity rather than threat and tries to manage the tensions (Miron-Spektor et al., 2018; Sparr, 2018).

In this study, grounded in a sense-making perspective, we develop a theoretical model that describes why and under what conditions paradoxical leadership may affect employees' task performance. According to sense-making theory, when individuals are faced with a situation, they try to comprehend it by creating their own explanations and meanings (Weick, 1995), which provide goals and motivations for subsequent actions (Drazin et al., 2008; Madjar et al., 2011). The role of paradoxical leadership is to help individuals interpret the competing demands positively (Miron-Spektor et al., 2018) and seek a synthesis method to improve outcomes. Such motivational orientation that may result from the interpretation of a situation is adaptability, which refers to the willingness and ability to change behaviors, feelings, and thoughts in response to environmental demands (McArdle et al., 2007). We predict that paradoxical leadership stimulates employees' task performance by increasing their adaptability.

Moreover, the explanations and meanings of situations are formed by an interactive combination of cultural values and individual identity (Weick, 1995; Weick et al., 2005; Drazin et al., 2008). Zhong Yong thinking represents a cognitive style that explains how the Chinese evaluate and process information, approach tasks, and make decisions (Yang, 2010). It enables individuals to process external information and integrate it with their internal need to take appropriate actions. Employees with Zhong Yong thinking are more likely to align their cognitions and behaviors with those of paradoxical leaders. Organizational identification is a form of collective work identity, referring to incorporating a group's beliefs and values into one's own identity and self-image (Pratt, 1998), which may affect individuals' information interpretation and motivation of actions. Accordingly, we examine Zhong Yong thinking and organizational identification as moderators that influence the relationship between paradoxical leadership and employee task performance.

This study makes several contributions to the literature. First, beyond commonly used theories for paradoxical leadership, such as paradox theory (e.g., Shao et al., 2019), yin-yang philosophy (e.g., Zhang et al., 2015), social learning theory (e.g., Ishaq et al., 2021), and self-determination theory (Yang et al., 2021), we introduce sense-making theory to broaden our understanding of the association between paradoxical leadership and employees' outcomes. According to sense-making theory, we argue that when leaders behave paradoxically in order effectively to manage demands that are not isolated but are inherently interrelated and in conflict with one another for the survival of the organization (Smith et al., 2012), they attempt to trigger organizational members' sense-making about what their jobs entail and how to do them (Lüscher and Lewis, 2008).

Second, we address the question of why paradoxical leadership is associated with task performance. When leaders engage in sense-giving, followers are not simply passive recipients of meaning but instead engage in their sense-making and adapt, alter, resist or reject the sense they have been given (Pratt, 2000; Sonenshein, 2010). However, the interpretations and efforts of employees have been overlooked, which highlights the necessity of examining adaptability as a mediating mechanism in our study. In addition, adopting a perspective of sensemaking in our study into the role of employee adaptability not only explains why paradoxical leadership enhances task performance but also translates the impact of paradoxical leadership to real outcomes.

Third, we propose and test the interactive effects of paradoxical leadership, Zhong Yong thinking, and organizational identification on adaptability and subsequent employee outcomes in the workplace. Our study contributes to the literature by identifying boundary conditions of the effect of paradoxical leadership. In doing so, we suggest that individual cultural values, such as Zhong Yong thinking, and work identity, such as organizational identification, may help them respond positively to the complex behavior of leaders and display high levels of task performance.

\section{THEORETICAL BACKGROUND AND HYPOTHESIS DEVELOPMENT}

\section{Paradoxical Leadership}

Paradoxical leadership is characterized by leader behaviors that are seemingly competing yet interrelated to meet competing workplace demands simultaneously and over time (Zhang et al., 2015). It requires leaders to reframe their thinking about contradictions from 'either/or' to 'both/and' (Smith and Berg, 1987). Paradoxical leadership is manifested in five pairs of contradictory behaviors (Zhang et al., 2015): (1) leader displays a combination of self-centerdness and othercenterdness when he or she maintains their central influence while simultaneously sharing recognition and leadership with followers. (2) Maintaining both distance and closeness is shown when a leader maintains hierarchical distinctions when dealing with work-related issues while simultaneously forming close relationships privately with subordinates. (3) Treating subordinates uniformly while allowing individualization is shown when a leader balances uniformity and individualization, such as assigning the same workloads, while simultaneously allocating different parts of the work based on individuals' skills or interests. (4) Enforcing work requirements while allowing flexibility is shown when a leader controls subordinates' behaviors and output while giving them the freedom to deal with problems flexibly and autonomously. (5) Finally, maintaining control over decisions while allowing autonomy, similar to enforcing work requirements while allowing flexibility, emphasizes the balance between control and empowerment.

Most research on paradoxical leadership has focused on its beneficial influence in organizations, as exemplified by improvements in performance (Smith and Lewis, 2011; Amason, 2017), creativity (Knight and Harvey, 2015), commitment (Smith, 2015), competitiveness (Fredberg, 2014; 
Derksen et al., 2017), the workplace environment (Lewis and Smith, 2014; Gnyawali et al., 2016; Knight and Paroutis, 2017) and career success (Derksen et al., 2017). In addition to its beneficial effects on organizations, research has shown that paradoxical leadership has positive influences on employees in terms of their work attitudes (Kan and Parry, 2004; Garg, 2016), work engagement (Alfes and Langner, 2017; Fürstenberg et al., 2021), work role performance (Zhang et al., 2015), creativity (Shao et al., 2019; Yang et al., 2021), and innovative behaviors (Milosevic et al., 2015; Ingram et al., 2016; Zhang et al., 2021). In summary, paradoxical leadership is widely considered to be an effective leadership style for managing the complex environments faced by modern organizations (Smith and Lewis, 2011; Zhang et al., 2015; Miron-Spektor et al., 2018).

\section{Paradoxical Leadership and Employee Task Performance}

Task performance refers to the role-prescribed activities of an employee (Borman and Motowidlo, 1993). It pertains to individuals' involvement in accomplishing assigned tasks by an enterprise (Motowidlo, 2000). Task performance is the foundation for organizations to survive. Leadership is a critical situational factor that affects employees' task performance (Hocine and Zhang, 2014). According to the sense-making theory, sense-making within an organization is related to understanding and is cognitive in nature (Gioia and Chittipeddi, 1991). Previous research on leadership has highlighted the importance of situation-specific cognition, which supports sensemaking and leadership as well as its influence on subordinates' outcomes (Lord and Hall, 2005; Mumford et al., 2007). In a complex and dynamic context, sense-making is seen as a key leadership capability (Ancona, 2011). The role of leaders is to serve as sense-givers. 'Sense-giving-for-others' is the process of making sense of this complex situation by themselves, then disseminating new understanding to subordinates to influence their 'sense-making-for-self' and subsequent devising a resolution to any situation (Foldy et al., 2008). Drawing on this argument, we suggest that paradoxical leaders may enhance employees' task performance by creating an environment that accepts contradiction as natural and persistent. Employees who make sense of paradoxical leader behavior may see conflicting and competing demands as intrinsic phenomena in organizations (Smith and Lewis, 2011; Miron-Spektor et al., 2018) and may bring different demands together such that the contradiction between them may transform into productive rather than intractable (Smith et al., 2012; Ingram et al., 2016). By serving as role models, paradoxical leaders allow their followers to observe how to deal constructively with paradoxical situations. Employees may work more confidently and purposefully by observing and modeling the leader's behaviors. Simultaneously, a paradoxical leader also provides support to reduce employees' paradox-related uncertainty (Maitlis and Sonenshein, 2010). For example, a leader may encourage employees to use new methods to increase output while accepting the possibility of failure. Taking these observations together, we propose the following hypotheses:
Hypothesis 1: Paradoxical leadership is positively related to employees' task performance.

\section{The Mediating Role of Employees' Adaptability}

The sense-making theory proposes that sense-making is triggered by failure to confirm one's self (Weick, 1995). Individuals construct their roles through ways that meet their needs for self-enhancement, self-efficacy and, self-consistency (Erez and Earley, 1993). When individuals feel their role in the organization threatened, they are triggered to engage in sense-making around the source of threat and take actions to recover their role (Maitlis and Christianson, 2014). An important characteristic of sensemaking is that it is based on extracted cues (Weick, 1995).

When facing a paradox, one fundamental role of a leader is to foster employee intrinsic motivation to build commitment and excitement for work (Andriopoulos and Lewis, 2009). We suggest that one way that paradoxical leaders influence employee task performance is through employee adaptability. Individual adaptability is one's ability, skill, disposition, willingness, or motivation to change or fit different the task, social, and environment features (Ployhart and Bliese, 2006). Adaptability is a positive motivational orientation toward changing oneself (Wang et al., 2017). Therefore, one of the biggest challenges facing leaders is to enable employees to adapt in the face of an increasingly dynamic and demanding environment (UhlBien and Arena, 2018). From this perspective, a paradoxical leader's role is to sense and shape opportunities and threats, and expect employees to adapt in accordance with their environment. Moreover, paradoxical leaders create supportive contexts in which individuals choose how and where to focus their energies (Uhl-Bien and Arena, 2018). For example, a paradoxical leader can communicate with subordinates to reduce their feelings of anxiety, uncertainty, and threat (Vince and Broussine, 1996; Lewis, 2000; Schad et al., 2016). A paradoxical leader also has a sharing attitude, which can influence subordinates' motivation willingness to adapt.

Adaptable employees have been found to exhibit less anxiety (Lewis and Smith, 2014) and to deal creatively with change (Miron-Spektor et al., 2011). Adaptable employees are also more likely to maintain positive affect and constructive behavior, even in uncertain situations (Sparr, 2018). Researchers have found that adaptable teams are more likely to generate new and innovative ideas (Axtell et al., 2000) and engage in job-crafting behaviors (Wang et al., 2017). In terms of task performance, we argue that adaptable employees may be motivated to act spontaneously to cope with paradoxes. Miron-Spektor et al. (2018) demonstrated that employees with a paradox mindset could help them to improve in-role job performance and innovation.

Taken together, we propose the following hypotheses:

Hypothesis 2: Employees' adaptability mediates the relationships between paradoxical leadership and task performance. 


\section{The Moderating Role of Zhong Yong Thinking}

Due to different historical traditions and regional cultures, Chinese people have great differences in thinking mode from Westerners. Chinese people usually look at problems from a holistic and dialectical point of view, while Westerners deal with problems analytically and pay attention to the characteristics of things themselves. Originating from Confucian philosophy, Zhong Yong thinking, also known as the doctrine of the mean, is defined as a cognitive style that requires individuals to consider things from different perspectives, recognize broader situations, avoids going to extremes, and maintain harmony (Ji et al., 2010). According to Wu and Lin (2005), Zhong Yong thinking consists of three features: holistic thinking, perspective integration and harmony maintenance. Holistic thinking refers to how individuals recognize things from different aspects; thus, holistic thinking can promote individuals to consider situations from a wide range of views so they can adjust to contradictory situations (Pan and Sun, 2018). Perspective integration refers to integrating of one's own opinion with those of others and seeking solutions that are acceptable to all by adopting compromising approaches to discussing problems (Ji et al., 2010). Harmony maintenance refers to developing harmonious relationships with others. A harmonious relationship demands that individuals understand the other's behavior and subsequently adjust one's own behavior (Pan and Sun, 2018). Therefore, Zhong Yong thinking offers an alternative cognitive style. By adopting a Zhong Yong thinking, individuals not only perceive and adjust their inner selves, but also change their behavior according to the different external environment ( $\mathrm{Wu}$ and Lin, 2005). For the external environment, Zhong Yong thinkers tend to consciously process the information they hear and integrate it with their internal needs, then choose the most appropriate behavior. This coincides with one of the characteristics of sense-making; that is, sense-making concerns the action that individuals take to make sense of a situation (Maitlis and Christianson, 2014). Individuals with Zhong Yong thinking make a continuous effort to understand connections among peoples, places, and events.

Employees receive contradictory and interdependent demands from their paradoxical leaders. Product developers, for example, are asked to consider cost issues and strictly follow specifications when developing new products. If employees have Zhong Yong thinking, they may have different interpretations, sensitivity and flexibility regarding the demands conveyed by a paradoxical leader. They may also think about how to integrate the leader's demand with their abilities and take appropriate action. As individuals with high Zhong Yong thinking seek a compromise between extremes (Yao et al., 2010), they will try to select cooperative strategies and compromises to stay consistent with their leaders' cognitions and behaviors. Subordinates of paradoxical leaders learn to increase their capacity to respond to a changing environment (Detert and Burris, 2007). The greater the Zhong Yong thinking of employees, the more a paradoxical leader's values, goals and norms will be internalized into their role cognitions and behaviors. In addition, due to the principle of holism, individuals with high Zhong Yong thinking will seek to deal creatively with change while simultaneously maintaining their efficiency (Miron-Spektor et al., 2011).

Therefore, we propose that Zhong Yong thinking enables employees to be more flexible and open to be consistent with paradoxical leadership, thereby becoming more actively accepting paradoxical leaders' efforts to achieve the best possible task performance.

Hypothesis 3 (H3): Zhong Yong thinking moderates the relationship between paradoxical leadership and employees' adaptability, such that the positive relationship is stronger for employees with high Zhong Yong thinking than for those with low Zhong Yong thinking.

Taking these hypotheses together, a moderated mediation model is formed in which the relationship between paradoxical leadership and subordinates' adaptability and the mediated relationship between paradoxical leadership and subordinates' task performance depending on the level of subordinates' Zhong Yong thinking. In other words, we propose that paradoxical leaders improve task performance by increasing adaptability, which is more likely to occur when individuals have a high level of Zhong Yong thinking. This leads to the following hypotheses:

Hypothesis 4: Employees' Zhong Yong thinking moderates the mediating effect of adaptability on the relationship between paradoxical leadership and task performance, such that the indirect effect of paradoxical leadership on task performance via adaptability is stronger for high Zhong Yong thinking than for low Zhong Yong thinking.

\section{The Moderating Role of Organizational Identification}

According to sense-making theory, a main characteristic of sense-making is that it is social, grounded in identity construction (Weick, 1995). sense-making can be difficult and lead to confusion without social roles and relationships within an organization (Weick, 1993). organizational identification represents common attributes that bind the individuals to their organizations (Dutton et al., 1994), which may influence individuals' issue-interpretation, meaning-creation, and engagement in creative actions toward their organizations (Madjar et al., 2011). And another important feature of sensemaking is that it is based on extracted cues (Weick, 1995), which indicates that individuals focus only on one part of their environment. Ford (1996) suggests that individuals tend to favor cues that are consistent with their personality. A paradoxical leader is part of the environment, which will influence employees' selection of environmental cues for adapting in the face of complex challenges. Therefore, we examine an interactive effect of paradoxical leadership (i.e., cue extraction) and organizational identification (i.e., identity construction) on employee adaptability.

Organizational identification is defined as the individual's sense of group or belonging to an organization in which an individual defines one's own identity as a member (Mael and Ashforth, 1992). The more an individual identifies with an 
organization, the more the organization's identity is incorporated into the individual's self-concept (Dutton et al., 1994). Employees with high organizational identification have a higher desire to enhance their self-concept, self-esteem, and self-worth to cope with a changing environment. Moreover, previous research on leadership has found that an employee's self-concept is a moderating factor in leadership processes (van Knippenberg et al., 2004; Wang et al., 2017). Consisting with this notion, we suggest that employees with high organizational identification can adjust to paradoxical leadership in a more positive way. Therefore, we propose:

Hypothesis 5 (H5): Employees organizational
identification moderates the relationship between
paradoxical leadership and employees adaptability, such
that the positive relationship is stronger for employees
with high organizational identification than for those with
low organizational identification.

We further suggest that employees' organizational identification moderates the indirect relationship between paradoxical leadership and task performance. Drawing on our discussion for Hypotheses 1, 2, and 5, we predict that for employees with a high level of organizational identification, paradoxical leadership will enhance adaptability, which in turn will promote performance outcomes. In contrast, for those with a low level of organizational identification, paradoxical leadership will hinder task performance by reducing adaptability.

Hypothesis 6: Employees' organizational identification
moderates the mediating effect of adaptability on the
relationship between paradoxical leadership and task
performance, such that the indirect effect of paradoxical
leadership on task performance via adaptability is stronger
for high organizational identification than for low
organizational identification.

The model we propose is illustrated in Figure 1.

\section{MATERIALS AND METHODS}

\section{Sample and Procedure}

To test our hypotheses, we used a multi-respondent crosssectional survey design to collect data. Data were collected from full-time employees, including employees and their immediate supervisors in 10 companies in southern China. These companies were all from high-tech industries. The research assistants handed out dyadic questionnaires that were filled out separately by supervisors and their subordinates, with the help of the human resource departments of each company. The covering letter of the questionnaires indicated that their data would be kept completely confidential and used only for scientific research.

Two separate surveys were administered for 1 month in order to reduce the influence of homologous error. At Time 1, the employees rated paradoxical leadership, adaptability, Zhong Yong thinking, and organizational identification. One month later, at Time 2, the supervisors rated their subordinates' task performance. At Time 1, a total of 315 employees filled in the questionnaire. At Time 2, a total of 268 supervisors filled in the questionnaire. After removing invalid responses, we had 235 unique supervisor-subordinate dyads who had completed questionnaires; the response rate was $74.6 \%$.

Among the participates, 159 (67.7\%) supervisors and 127 $(54.0 \%)$ subordinates were male. The mean age of supervisors was 36.09 years $(S D=5.73)$ and of subordinates 30.34 years $(S D=5.47)$. About $95.3 \%$ of supervisors and $82.5 \%$ of subordinates had college or higher degrees. On average, supervisors had 5.29 years $(S D=2.86)$ of work experience in their current company, and subordinates on average had worked for 3.89 years $(S D=4.45)$ in their current company.

\section{Ethical Statement}

Before starting data collection, ethical approval was applied and approved by the Academic Committee of the University. All procedures performed in studies involving human participants did not violate any legal regulations or common ethical guidelines. In order to ensure that ethical principles are followed in this study, the purpose of this research was introduced and informed consent was obtained from all individual participants included in the study. Moreover, all participants were assured that they could reject any questions or withdraw from the survey at any time. Lastly, individual participants' anonymity and confidentiality were assured.

\section{Measures}

\section{Paradoxical Leadership}

We used the twenty-two items developed by Zhang et al. (2015) to measure paradoxical leadership behavior. The scale contains five dimensions: combining self-centerdness with othercenteredness; maintaining both distance and closeness; treating subordinates uniformly while allowing individualization; enforcing work requirements while allowing flexibility; and maintaining decision control while allowing autonomy. Employees were asked to rate their leader's paradoxical leadership behavior. A sample item was 'Uses a fair approach to treat all subordinates uniformly, but also treats them as individuals.' All items were rated on a 5-point Likert scale ranging from 'strongly disagree' (1) to 'strongly agree' (5). Cronbach's $\alpha$ of five dimensions were $\mathrm{UI}=0.86, \mathrm{SO}=0.83$, $\mathrm{CA}=0.89, \mathrm{RF}=0.85, \mathrm{DC}=0.88$.

\section{Adaptability}

We used the nine items developed by Van der Heijde and Van der Heijden (2006) and shortened by Van der Heijden et al. (2018) to measure subordinates' adaptability. According to Van der Heijde and Van der Heijden (2006), subordinates' adaptability contains two dimensions: anticipation and optimization, and personal flexibility. Anticipation and optimization were measured with four items. A sample item was 'I consciously devote attention to applying my newly acquired knowledge and skills.' Personal flexibility was measured with five items. A sample item was 'I adapt to developments within my organization.' All items were rated on a 5-point Likert scale ranging from 'strongly disagree' 


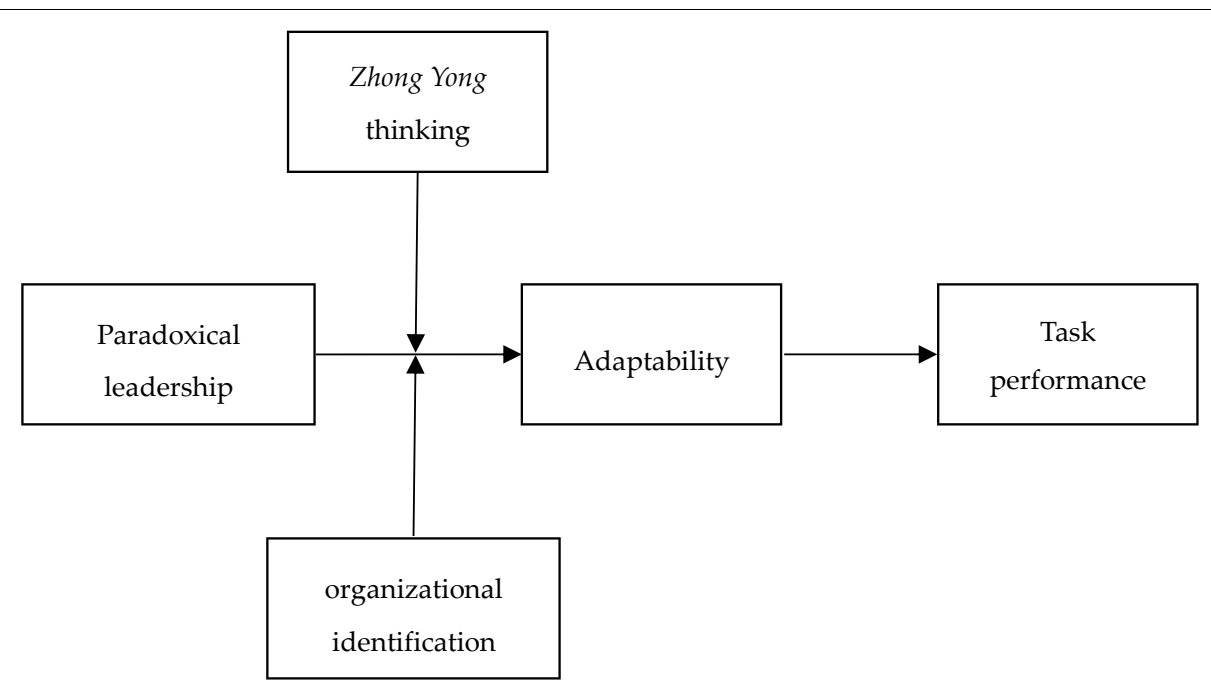

FIGURE 1 | Conceptual model.

(1) to 'strongly agree' (5). Cronbach's $\alpha$ of two dimensions were $\mathrm{AO}=0.85, \mathrm{PF}=0.83$.

\section{Task Performance}

We used the three items developed by Farh et al. (1991) to measure task performance. Supervisors were asked to rate their direct subordinates' task performance from three aspects: work quality, work efficiency and the completion of the work target. A sample item was 'Are your subordinate's work outcomes perfect, free of error and of high accuracy?' All items were rated on a 5-point Likert scale ranging from 'strongly disagree' (1) to 'strongly agree' (5). Cronbach's $\alpha$ was 0.79 .

\section{Zhong Yong Thinking}

We used the thirteen items developed by $\mathrm{Wu}$ and Lin (2005) to measure Zhong Yong thinking. The scale contains three dimensions: holistic thinking, perspective integration and harmony. The participants were asked to report their own Zhong Yong thinking. A sample item was 'I try to find a balance between my own opinions and those of others.' All items were rated on a 5point Likert scale ranging from 'strongly disagree' (1) to 'strongly agree' (5). Cronbach's $\alpha$ of three dimensions were $\mathrm{HT}=0.89$, $\mathrm{PI}=0.86, \mathrm{HM}=0.87$.

\section{Organizational Identification}

We used the five items developed by Smidts et al. (2001) to measure employees' organizational identification. Employees were asked to report their own organizational identification. A sample item was 'I experience a strong sense of belonging to my company.' All items were rated on a 5-point Likert scale ranging from 'strongly disagree' (1) to 'strongly agree' (5). Cronbach's $\alpha$ was 0.94 .

\section{Control Variables}

For assessing predictive validity, we considered several relevant control variables, such as gender $(0=$ female, $1=$ male $)$, and educational level ( $1=$ high school degree or less, $2=$ practical degree, 3 = bachelor's, 4 = master's or higher). We also controlled for the organizational tenure of the supervisors and employees, both of which might have an influence on the interaction between them.

\section{RESULTS}

\section{Confirmatory Factor Analysis}

We used Amos 21.0 to conduct confirmatory factor analysis (CFA) to test the factorial validity of our measures through maximum likelihood estimation. The measurement model consisted of all measured variables, including paradoxical leadership (UI, treating subordinates uniformly while allowing individualization; SO, combining self-centeredness with othercenteredness; CA, maintaining decision control while allowing autonomy; RF, enforcing work requirements while allowing flexibility; DC, maintaining both distance and closeness), adaptability (AO, anticipation and optimization; PF, personal flexibility), Zhong Yong thinking (HT, holistic thinking; $\mathrm{PI}$, perspective integration; HM, harmony), organizational identification, task performance and creativity. A total of variables/dimensions of were taken as latent variables, and the items of each variable/dimension were taken as explicit variables. The reliability and validity of our study questionnaire were evaluated by calculating composition reliability (CR) and average variance extracted (AVE) through the factor loading of CFA.

For this study, the standardized factor loading of the variables/dimensions was between 0.529 and 0.929. Cronbach's $\alpha$ ranged from 0.789 to 0.944 . The CR ranged from 0.791 to 0.945 and the AVE was between 0.511 and 0.775 (see Table 1). They were all in line with the recommended values given by Fornell and Larcker (1981): the standardized factor loading was greater than 0.5 , the AVE should be greater than 0.5 , and the CR was greater than 0.6 . The test results of discriminate validity showed that each square root of AVE ranged from 0.715 to 0.880 (see 
TABLE 1 | Internal consistency reliability, composition reliability, convergent validity, and discriminant validity.

\begin{tabular}{|c|c|c|c|c|c|c|c|c|}
\hline \multirow[t]{2}{*}{ Variables } & \multirow[t]{2}{*}{ Factor } & \multirow[t]{2}{*}{ Item } & \multirow[t]{2}{*}{ Factor loading } & \multicolumn{2}{|c|}{ Reliability } & \multirow{2}{*}{$\frac{\text { Convergent validity }}{\text { AVE }}$} & \multicolumn{2}{|c|}{ Discriminant validity } \\
\hline & & & & $\alpha$ & CR & & $\mathbf{r}$ & Square root of $\mathrm{AVE}$ \\
\hline \multirow[t]{5}{*}{ Paradoxical leadership } & UI & PL1 PL5 & $0.559 \sim 0.858$ & 0.856 & 0.864 & 0.564 & $0.080 \sim 0.762$ & 0.751 \\
\hline & SO & PL6 PL10 & $0.559 \sim 0.811$ & 0.832 & 0.839 & 0.515 & $0.094 \sim 0.762$ & 0.718 \\
\hline & CA & PL11 PL14 & $0.737 \sim 0.869$ & 0.892 & 0.893 & 0.677 & $0.137 \sim 0.614$ & 0.823 \\
\hline & $\mathrm{RF}$ & PL15 PL18 & $0.735 \sim 0.803$ & 0.852 & 0.854 & 0.594 & $0.103 \sim 0.604$ & 0.771 \\
\hline & DC & PL19 PL22 & $0.765 \sim 0.835$ & 0.875 & 0.877 & 0.642 & $0.098 \sim 0.604$ & 0.801 \\
\hline \multirow[t]{3}{*}{ Zhong Yong thinking } & HT & $Z Y 1 \sim Z Y 4$ & $0.772 \sim 0.899$ & 0.887 & 0.888 & 0.666 & $0.077 \sim 0.760$ & 0.816 \\
\hline & $\mathrm{PI}$ & ZY5 ZY9 & $0.564 \sim 0.826$ & 0.856 & 0.861 & 0.558 & $0.094 \sim 0.831$ & 0.747 \\
\hline & $\mathrm{HM}$ & $Z Y 10 \sim Z Y 13$ & $0.687 \sim 0.819$ & 0.871 & 0.876 & 0.640 & $0.080 \sim 0.831$ & 0.800 \\
\hline Organizational identity & $\mathrm{Ol}$ & $\mathrm{Ol1} \sim \mathrm{Ol5}$ & $0.799 \sim 0.929$ & 0.944 & 0.945 & 0.775 & $0.204 \sim 0.914$ & 0.880 \\
\hline \multirow[t]{2}{*}{ Adaptability } & $\mathrm{AO}$ & $\mathrm{AD} 1 \sim \mathrm{AD} 4$ & $0.618 \sim 0.860$ & 0.853 & 0.857 & 0.603 & $0.195 \sim 0.914$ & 0.777 \\
\hline & $\mathrm{PF}$ & AD5 AD9 & $0.529 \sim 0.836$ & 0.833 & 0.836 & 0.511 & $0.110 \sim 0.360$ & 0.715 \\
\hline Task performance & $\mathrm{TP}$ & TP1 TP3 & $0.727 \sim 0.761$ & 0.789 & 0.791 & 0.557 & $0.077 \sim 0.396$ & 0.746 \\
\hline
\end{tabular}

Table 1), which is greater than the correlation coefficient between the constructs and meets the criteria suggested by Fornell et al. (1982). This finding indicates that the questionnaire developed in this study had high internal consistency reliability, composition reliability, convergence validity and discriminant validity.

In order to control the common-method variance, we collected data at two time points, since the independent variable 'paradoxical leadership' and the mediator 'adaptability' were answered by employees at the same time, the problem of the homologous variance may exist. So we adopted method such as concealment of survey content and information of respondents, setting reverse questions, and different scales (Likert-5, Likert$7)$ to reduce response tendency in the survey. The fit indices of the CFA $\left(\chi^{2}=1736.608, \mathrm{df}=1208, \mathrm{CFI}=0.931\right.$, TLI $=0.924$, RMSEA $=0.043$, SRMR $=0.049$ ) are all acceptable (lower than 0.95), indicating that the confirmatory factor model we constructed is scientific and reasonable (see Table 2).

The means, standard deviations and correlations are shown in Table 3. The results showed that paradoxical leadership was positively related to adaptability $(r=0.33, p<0.01)$ and task performance $(r=0.28, p<0.01)$. Thus, our hypotheses received preliminary support.

\section{Hypothesis Testing}

We adopted a stepwise regression method to test our hypotheses. The results are shown in Table 4. First, the results of Model 9 indicated that paradoxical leadership had a positive relationship with task performance $(\beta=0.29, p<0.001)$; the total effect of paradoxical leadership on task performance was significant. H1 was supported; Second, Model 2 indicated that paradoxical leadership had a positive relationship with adaptability $(\beta=0.33$,

TABLE 2 | Indices of model fit.

\begin{tabular}{lccccccc}
\hline Index of model fit & $\chi^{2}$ & df & $\chi^{2} /$ df & CFI & TLI & RMSEA & SRMR \\
\hline \multirow{2}{*}{ Results } & - & - & $<3$ & $>0.9$ & $>0.9$ & $<0.08$ & $<0.08$ \\
& 1736.608 & 1208 & 1.438 & 0.931 & 0.924 & 0.043 & 0.049
\end{tabular}

$p<0.001)$; Third, Model 10 indicated that paradoxical leadership and adaptability had a positive relationship with task performance $(\beta=0.21, p<0.01 ; \beta=0.26, p<0.001)$. The results indicated that adaptability plays a partial mediating role in the relationship between paradoxical leadership and task performance. To further test the mediating effect of adaptability, we adopted the test method proposed by Preacher et al. (2007), using bootstrapping with the SPSS Process. The results of bootstrapping showed that the indirect effect was significant $(\mathrm{a} \times \mathrm{b}=0.130), 95 \%$ confidence interval [LLCI $=0.060$, $\mathrm{ULCI}=0.220]$. Therefore, $\mathrm{H} 2$ was supported.

To examine the moderating effect of Zhong Yong thinking and organizational identification, we followed the suggestion of Cohen et al. (2003). We first centralized the independent variable 'paradoxical leadership', the moderator variables 'Zhong Yong thinking' and 'organizational identification,' and then respectively constructed the interaction items 'paradoxical leadership' and 'Zhong Yong thinking, and 'paradoxical leadership' and 'organizational identification.' As shown in Table 4, Model 2 indicated that paradoxical leadership had a positive relationship with adaptability $(\beta=0.33, p<0.001)$. In Model 4 , we put 'paradoxical leadership' and 'Zhong Yong thinking' into the regression equation model at the same time, and results showed that paradoxical leadership still had a positive relationship with adaptability $(\beta=0.28, p<0.001)$, and the interaction between 'paradoxical leadership' and 'Zhong Yong thinking' had a positive relationship with adaptability $(\beta=0.24, p<0.001)$. To better understand the moderating effect, according to the suggestion of Cohen et al. (2003), we used Process program by Hayes and Usami $(2020)^{1}$ to conduct a simple slope test. Figure 2 shows that paradoxical leadership was more positively related to adaptability when Zhong Yong thinking was high than when it was low. Therefore, H3 was supported.

We further tested the moderating effect of organizational identification. On the basis of Model 2, we put 'paradoxical leadership' and 'organizational identification' into the regression equation model at the same time (Model 6), and results showed

${ }^{1}$ http://www.processmacro.org/download.html 
TABLE 3 | Descriptive statistics and correlation coefficient matrix.

\begin{tabular}{|c|c|c|c|c|c|c|c|c|c|}
\hline \multirow[t]{2}{*}{ Variables } & \multirow[t]{2}{*}{$M$} & \multirow[t]{2}{*}{$S D$} & \multicolumn{7}{|c|}{ Correlations } \\
\hline & & & 1 & 2 & 3 & 4 & 5 & 6 & 7 \\
\hline (1) Gender & 0.68 & 0.47 & 1 & & & & & & \\
\hline (2) Organizational Tenure (year) & 5.29 & 2.86 & 0.00 & 1 & & & & & \\
\hline (3) Education & 3.26 & 0.55 & -0.10 & 0.05 & 1 & & & & \\
\hline (4) $\mathrm{PL}$ & 3.87 & 0.48 & -0.01 & 0.08 & 0.08 & 1 & & & \\
\hline (5) $Z Y T$ & 2.13 & 0.63 & -0.03 & 0.04 & -0.04 & $0.17^{* *}$ & 1 & & \\
\hline (6) Organization Identification & 3.91 & 0.82 & -0.03 & -0.01 & -0.06 & $0.32^{* *}$ & $0.35^{\star *}$ & 1 & \\
\hline (7) Adaptability & 3.87 & 0.61 & -0.03 & -0.03 & 0.07 & $0.33^{\star \star}$ & $0.26^{\star \star}$ & $0.33^{\star \star}$ & 1 \\
\hline (8) Task performance & 3.99 & 0.72 & -0.03 & -0.06 & -0.05 & $0.28^{* \star}$ & 0.09 & 0.09 & $0.32^{\star \star}$ \\
\hline
\end{tabular}

$n=235.0$ female; $1=$ male; $P L$, paradoxical leadership; ZYT, Zhong Yong thinking.

${ }^{*} p<0.05,{ }^{* *} p<0.01$.

TABLE 4 | Analysis of regression.

\begin{tabular}{|c|c|c|c|c|c|c|c|c|c|c|}
\hline & \multicolumn{6}{|c|}{ Adaptability } & \multirow[b]{2}{*}{ M7 } & \multicolumn{3}{|c|}{ Task performance } \\
\hline & M1 & M2 & M3 & M4 & M5 & M6 & & M8 & M9 & M10 \\
\hline Gender & -0.02 & -0.02 & -0.01 & 0.00 & -0.01 & 0.01 & 0.02 & -0.03 & -0.03 & -0.03 \\
\hline Tenure(year) & -0.03 & -0.06 & -0.06 & -0.05 & -0.05 & -0.07 & -0.01 & -0.06 & -0.08 & -0.07 \\
\hline Education & 0.06 & 0.04 & 0.05 & 0.06 & 0.06 & 0.05 & 0.07 & -0.05 & -0.07 & -0.08 \\
\hline PL & & $0.33^{\star \star \star}$ & $0.29^{\star \star \star}$ & $0.28^{\star \star \star}$ & $0.25^{\star \star \star}$ & $0.28^{\star \star \star}$ & $0.20^{\star \star \star}$ & & $0.29^{\star \star \star}$ & $0.21^{\star \star}$ \\
\hline $\mathrm{ZYT}$ & & & $0.22^{\star \star}$ & $0.20^{\star \star}$ & & & $0.11^{\star \star}$ & & & \\
\hline Ol & & & & & $0.25^{\star \star \star}$ & $0.27^{\star \star \star}$ & 0.04 & & & \\
\hline Adaptability & & & & & & & & & & $0.26^{\star \star \star}$ \\
\hline PLXZYT & & & & $0.24^{\star \star \star}$ & & & $0.16^{\star \star \star}$ & & & \\
\hline PLxOI & & & & & & $0.32^{\star \star \star}$ & $0.13^{\star \star \star}$ & & & \\
\hline ZYTxOI & & & & & & & $-0.18^{\star \star \star}$ & & & \\
\hline PLxZYTxOI & & & & & & & -0.02 & & & \\
\hline$R^{2}$ & 0.01 & 0.11 & 0.16 & 0.21 & 0.17 & 0.27 & 0.35 & 0.01 & 0.09 & 0.15 \\
\hline$\Delta R^{2}$ & & $0.11^{\star \star \star}$ & $0.05^{\star \star}$ & $0.06^{\star \star \star}$ & $0.06^{\star \star \star}$ & $0.10^{\star \star \star}$ & $0.35^{\star \star \star}$ & & $0.08^{\star \star \star}$ & $0.06^{\star \star \star}$ \\
\hline$F$ & 0.44 & $7.40^{\star \star \star}$ & $8.66^{\star \star \star}$ & $10.33^{\star \star \star}$ & $9.29^{\star \star \star}$ & $14.16^{\star \star \star}$ & $17.32^{\star \star \star}$ & 0.52 & $5.68^{\star \star \star}$ & $7.99^{\star \star \star *}$ \\
\hline
\end{tabular}

$n=235$.

$P L$, paradoxical leadership; ZYT, Zhong Yong thinking; Ol, organizational identification.

${ }^{*} p<0.05,{ }^{* *} p<0.01,{ }^{* * *} p<0.001$.

that paradoxical leadership still had a positive relationship with adaptability $(\beta=0.28, p<0.001)$, and the interaction between paradoxical leadership and organizational identification had a positive relationship with adaptability $(\beta=0.32, p<0.001)$. Figure 3 shows that paradoxical leadership was more positively related to adaptability when organizational identification was high than when it was low. Therefore, H5 was supported.

In order to test the robustness of the results, we controlled for the three-way interaction (and the interactive term of Zhong Yong thinking and organizational identification) in the regression analysis (Model 7), results showed that paradoxical leadership still had a positive relationship with adaptability ( $\beta=0.20, p<0.001)$, and the interaction between paradoxical leadership and Zhong Yong thinking, paradoxical leadership and organizational identification still had a positive relationship with adaptability $(\beta=0.16, p<0.001 ; \beta=0.13, p<0.001)$.

As shown in Table 5, when Zhong Yong thinking was at a low level, the indirect effect of paradoxical leadership on task performance via adaptability was not significant (effect $=0.03$, 95\% CI $[-0.04,0.10])$. When Zhong Yong thinking was at a high level, the results were significant (effect $=0.18,95 \%$ CI $[0.09$, 0.31]). By comparing the difference mediating effect of each level, we found that confidence interval of mediating effect difference between high and low level did not contain zero (effect $=0.16$, $95 \%$ CI $[0.06,0.30])$, indicating the mediating effect of each level was significantly different. Moreover, the moderated mediation effect was 0.12 , and the $95 \%$ CI was $[0.05,0.24]$; neither contained zero. These results indicated that the indirect effect of paradoxical leadership on task performance via adaptability was moderated by Zhong Yong thinking. Taken together, H4 was supported.

Similarly, as shown in Table $\mathbf{6}$, when organizational identification was at a low level, the indirect effects of paradoxical leadership on task performance via adaptability was not significant $($ effect $=0.0004,95 \%$ CI $[-0.05,0.06]$ ). When organizational identification was at a high level, the results were significant $($ effect $=0.22,95 \%$ CI $[0.11,0.35])$. By comparing 


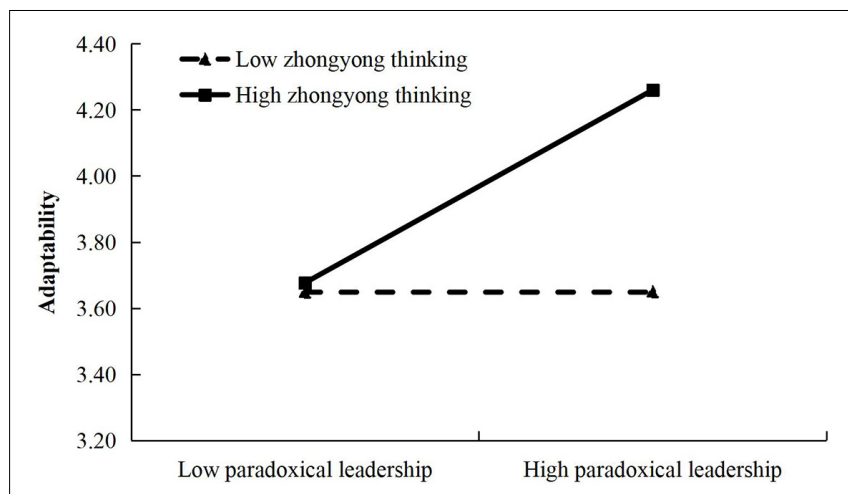

FIGURE 2 | Interaction effect of paradoxical leadership and Zhong Yong thinking.

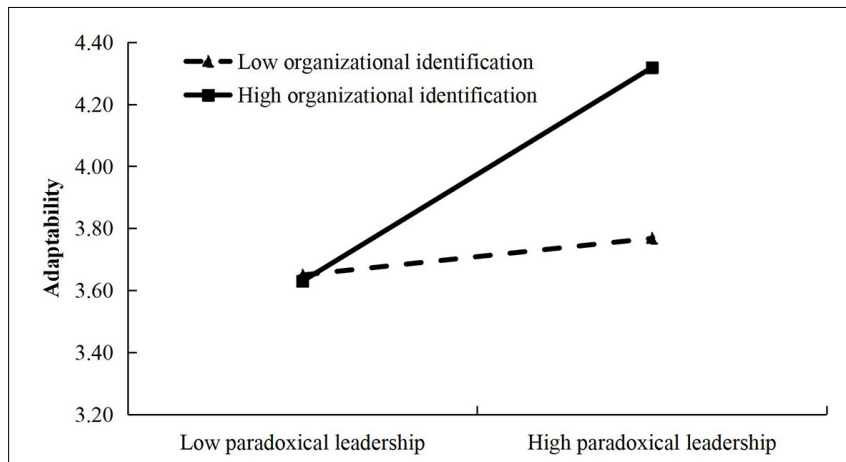

FIGURE 3 | Interaction effect of paradoxical leadership and organizational identification.

the difference mediating effect of each level, we found that the confidence interval of mediating effect difference between high and low level did not contain zero (effect $=0.22$, 95\%CI $[0.10,0.34])$, indicating the mediating effect of each level was significantly different. Moreover, the moderated mediation effect was 0.13 , and the $95 \%$ CI was $[0.06,0.21]$, neither contained zero. These results indicated that the indirect effect of paradoxical leadership on task performance and creativity via adaptability was moderated by organizational identification. Taken together, H6 was supported.

\section{DISCUSSION}

Based on sense-making theory, we developed and tested a model to examine how paradoxical leadership affects employee performance outcomes via enhancing employee adaptability, and how employee Zhong Yong thinking and organizational identification influence the effectiveness of paradoxical leadership. The results of a questionnaire survey of 235 sets of paired data from supervisors and their direct subordinates found that paradoxical leadership promoted employees' adaptability, thereby improving followers' performance outcomes. Moreover, the results supported the conditional indirect effects of paradoxical leadership on task performance.

\section{Theoretical Implications}

Despite the fact that paradoxical challenges are pervasive in organizations at both the organization level (Smith and Lewis, 2011; Schad et al., 2016) and the employee level (Zhang et al., 2015; Shao et al., 2019; Fürstenberg et al., 2021), the effectiveness of leaders is becoming a central issue for organizations to embrace inconsistencies and seek sustainable development. Our study makes several contributions to the literature. First, our study extends and adds value to the sense-making theory by linking it with paradoxical leadership. Although a variety of theoretical perspectives-such as paradox theory, yin-yang philosophy, social learning theory and self-determination theory-have been used to explain the impacts of paradoxical leadership on employees motivations and behaviors at work, this line of study has mostly focused on what specific leader behaviors can promote adaptability and when. In particular, it reveals that leaders can promote the adaptability of their followers by adopting a "both/and" approach to trigger followers to engage in sense-making around the sources of opportunities and threats and act so as to restore their identity in the face of dynamic and complex environment (Maitlis and Christianson, 2014). Such a leadership approach improves employee adaptability and subsequent task performance depending on individual cultural factors and organizational context factors. Taking together, our findings extend sense-making theory by demonstrating how paradoxical leaders trigger their members' sensemaking about the organizational environment and how to do (Lüscher and Lewis, 2008).

Second, we take a step toward resolving a critical argument about how paradoxical leadership help individuals address task performance outcomes in complicated and conflicted environment. Several studies have recognized that sense-making is initiated when leaders arrive with a vision for the organization in response to environment changes (Ravasi and Schultz, 2006; Nag et al., 2007). Thus, sense-making by individuals occur

TABLE 5 | Moderated mediation results of Zhong Yong thinking.

\begin{tabular}{lcccccc}
\hline & $\begin{array}{c}\text { Zhong Yong } \\
\text { thinking }\end{array}$ & Effect & BootSE & & \multicolumn{2}{c}{$\mathbf{9 5 \%}$ Cl } \\
\cline { 5 - 7 } & & & & LLCl & ULCI \\
\hline Conditional indirect effects & Low(-1 SD) & 0.03 & 0.03 & -0.04 & 0.10 \\
& High(+1 SD) & 0.18 & 0.05 & 0.09 & 0.31 \\
Difference (High-Low) & & 0.16 & 0.06 & 0.06 & 0.30 \\
Index of moderated mediation & 0.12 & 0.05 & 0.05 & 0.24
\end{tabular}

TABLE 6 | Moderated mediation results of organizational identification.

\begin{tabular}{lcccccc}
\hline & $\begin{array}{c}\text { Organizational } \\
\text { identification }\end{array}$ & Effect & BootSE & \multicolumn{2}{c}{$\mathbf{9 5 \%} \mathbf{~ C l}$} \\
\cline { 4 - 7 } & & & & LLCl & ULCl \\
\hline Conditional indirect effects & Low(-1 SD) & 0.0004 & 0.03 & -0.05 & 0.06 \\
\cline { 4 - 6 } & High(+1 SD) & 0.22 & 0.06 & 0.11 & 0.35 \\
Difference(High-Low) & & 0.22 & 0.06 & 0.10 & 0.34 \\
Index of moderated mediation & 0.13 & 0.04 & 0.06 & 0.21
\end{tabular}


in response to leader's sensegiving which shape members' understanding of a positive way forward. This positive way is the individuals' willingness to adapt to a leader's behavior, and to be more flexible and open to be consistent with paradoxical leadership, to overcome challenges and changes. Therefore, we highlight the necessity of examining adaptability as a mediating mechanism in our study.

Third, following the sense-making theory, we contribute to the literature on leadership by extending the boundary conditions under which paradoxical leadership are more effective. Specifically, the empirical results show that two important boundary conditions (Zhong Yong thinking and organizational identification) are the two factors that affect the effectiveness of paradoxical leadership. In other words, paradoxical leadership tends to elicit a high level of individual adaptability in dynamic cognitions rather than in stable cognitions in that Zhong Yong thinkers tend to consciously process the external information with their internal needs. This is consistent with the suggestion by Miron-Spektor et al. (2018) that the importance of employees' paradox mindset in responding to organizational paradox is triggered by resource scarcity. Moreover, our treatment of organizational identification as a moderator also makes a contribution to identity literature. We find that the effect of organizational identification is sufficient to make paradoxical leadership conducive to employee adaptability and subsequent performance outcomes. This means, even if paradoxical leaders serve as sensegivers to influence their subordinates, the sense-making by their followers may also fail when the organization's identity is not incorporated into the individual's self-concept. This result is also consistent with the assertion by Maitlis and Christianson (2014) that individuals are motivated to make changes in their own roles and actions when leaders are successful in influencing the sense-making of them. Taking together, our results suggest that with high levels of Zhong Yong thinking or high levels of organizational identification, paradoxical leadership may be sufficient for employees to fulfill their self-enhancement needs.

\section{Practical Implications}

As organizational environments become more complex, fastpaced and competitive, organizations increasingly confront diverse paradoxical tensions. Leaders and employees seek coping strategies to deal with these paradoxical tensions. Our study may illuminate such strategies.

First, we highlight the importance for both leaders and employees of a paradox mindset to deal with contradictory demands. As prior research has suggested, coping with paradoxes is becoming an increasingly important skill (Zhang et al., 2015; Miron-Spektor et al., 2018). Second, our findings of the mediation effect of adaptability shows leaders that an effective way to increase performance is to improve employee adaptability. Developing paradoxical leadership may be an effective way for organizations to increase employee adaptability to promote positive outcomes. Finally, managers aiming to increase performance should be aware of different boundary conditions, such as culture. Employees who endorse traditional Chinese cultures will tend to understand leaders' behaviors and reframe change in a positive way. For example, previous research has shown that Zhong Yong thinking guides employees in managing their meta-cognitions and preventing the disruptive effects of change (Pan and Sun, 2018). Managers should give such employees complex tasks and the discretion to act flexibly and autonomously. Moreover, rather than focusing on avoiding workplace contradictions, organizations should encourage greater organizational identification. Leaders' sensemaking and sensegiving is an effective route to identification (Gioia and Chittipeddi, 1991; Ashforth et al., 2008). Managers can enhance the prestige of the organization through the exchange of organizational information with employees, so that the identification of the organization becomes a contributor to the employees' self-enhancement needs (Smidts et al., 2001).

\section{Limitations and Future Research}

Admittedly, this study has several limitations. First, our multirespondent cross-sectional data collection design by which we collected paradoxical leadership and employee adaptability at a single timepoint may cause common-method variance. Thus, future research should consider longitudinal or threewave cross-sectional designs for data collection to replicate and extend the current research. Moreover, the CFI and TLI values in CFA are lower than 0.95. Future research should expand the sample size to improve the indices of model fit. Second, our research was based on a Chinese context, examining the influence mechanism of paradoxical leadership on performance outcomes from the perspective of individuals' psychological processes. Future research could consider the differences between Chinese and Western situations when facing paradoxes. Third, we focused on individual differences and organizational context factors as boundary conditions that may affect the effectiveness of paradoxical leadership. Future research could explore other contextual variables that influence the effect of paradoxical leadership on employee outcomes.

\section{DATA AVAILABILITY STATEMENT}

The raw data supporting the conclusions of this article will be made available by the authors, without undue reservation.

\section{ETHICS STATEMENT}

The studies involving human participants were reviewed and approved by Hubei University's Ethics Committee. The patients/participants provided their written informed consent to participate in this study.

\section{AUTHOR CONTRIBUTIONS}

WZ developed the research model, analyzed the data, and co-drafted the manuscript. SL provided the constructive 
suggestions to the research design, collected the data, and codrafted the manuscript. JL participated in the data analysis and edited the manuscript. QZ edited the manuscript. All authors listed have made a substantial, direct, and intellectual contribution to the work, and approved it for publication.

\section{REFERENCES}

Alfes, K., and Langner, N. (2017). Paradoxical leadership: understanding and managing conflicting tensions to foster volunteer engagement. Organ. Dyn. 46, 96-103. doi: 10.1016/j.orgdyn.2017.04.005

Amason, A. C. (2017). Distinguishing the effects of functional and dysfunctional conflict on strategic decision making: resolving a paradox for top management teams. Acad. Manag. J. 39, 123-148. doi: 10.5465/256633

Ancona, D. (2011). "Sensemaking: framing and acting in the unknown," in The Handbook for Teaching Leadership, eds S. Snook, N. Nohria, and R. Khurana (Thousand Oaks, CA: Sage Publications), 3-19.

Andriopoulos, C., and Lewis, M. W. (2009). Exploitation-exploration tensions and organizational ambidexterity: managing paradoxes of innovation. Organ. Sci. 20, 696-717. doi: $10.1287 /$ orsc. 1080.0406

Ashforth, B. E., Harrison, S. H., and Corley, K. G. (2008). Identification in organizations: an examination of four fundamental questions. J. Manage. 34, 325-374. doi: 10.1177/0149206308316059

Axtell, C. M., Holman, D. J., Unsworth, K. L., Wall, T. D., and Waterson, P. E. (2000). Shopfloor innovation: facilitating the suggestion and implementation of ideas. J. Occup. Organ. Psychol. 73, 265-285. doi: 10.1348/09631790016 7029

Borman, W. C., and Motowidlo, S. J. (1993). "Expanding the criterion domain to include elements of contextual performance," in Personnel Selection In Organizations, eds N. Schmitt and W. C. Borman (San Francisco: Jossey-Bass).

Cohen, J., Cohen, P., West, S. G., and Aiken, L. S. (2003). Applied Multiple Regression/Correlation Analysis For The Behavioral Sciences (3rd ed.). Mahwah: Erlbaum.

Derksen, K., Blomme, R. J., de Caluwé, L., Rupert, J., and Simons, R. J. (2017). Breaking the Paradox: understanding How Teams Create Developmental Space. J. Manag. Inq. 28, 366-380. doi: 10.1177/1056492617718090

Detert, J. R., and Burris, E. R. (2007). Leadership behavior and employee voice: is the door really open?. Acad. Manag. J. 50, 869-884. doi: 10.5465/amj.2007. 26279183

Drazin, R., Kazanjian, R. K., and Glynn, M. A. (2008). "Creativity and sensemaking among professionals," in Handbook Of Organizational Creativity, eds J. Zhou and C. E. Shalley (New York: Erlbaum), 263-281.

Dutton, J. E., Dukerich, J. M., and Harquail, C. V. (1994). Organizational images and member identification. Adm. Sci. Q. 39, 239-263. doi: 10.2307/2393235

Erez, M., and Earley, C. P. (1993). Culture, Self-Identity, and Work. New York: Oxford University Press. doi: 10.1093/acprof:oso/9780195075809.001.0001

Farh, J. L., Dobbins, G. H., and Cheng, B. S. (1991). Cultural Relativity in Action: A Comparison of Self-Ratings Made by Chinese and U.S. Workers. Pers. Psychol. 44, 129-147. doi: 10.1111/j.1744-6570.1991.tb00693.x

Foldy, E. G., Goldman, L., and Ospina, S. (2008). Sensegiving and the role of cognitive shifts in the work of leadership. Leadersh. Q. 19, 514-529. doi: 10.1016/j.leaqua.2008.07.004

Ford, C. M. (1996). A theory of individual creative action in multiple social domains. Acad. Manag. Rev. 21, 1112-1142. doi: 10.3389/fpsyg.2017.02169

Fornell, C., and Larcker, D. (1981). Evaluating structural equation models with unobservable variables and measurement error. J. Mark. Res. 18, 39-50. doi: $10.1177 / 002224378101800104$

Fornell, C., Tellis, G. J., and Zinkhan, G. M. (1982). "Validity assessment: A structural equations approach using partial least squares," in An Assessment of Marketing Thought and Practice, ed. B. J. Walker (Chicago: American Marketing Association).

Fredberg, T. (2014). If I Say it's Complex, It Bloody Well Will Be: CEO Strategies for Managing Paradox. J. Appl. Behav. Sci. 50, 171-188. doi: 10.1177/ 0021886314522859

\section{FUNDING}

This work was supported by the Young Scientists Fund of the National Natural Science Foundation of China (Grant No. 71802073) and National Natural Science Foundation Key Program of China (Grant No. 71832004).

Fürstenberg, N., Alfes, K., and Kearney, E. (2021). How and when paradoxical leadership benefits work engagement: the role of goal clarity and work autonomy. J. Occup. Organ. Psychol. 94, 672-705.

Garg, V. (2016). Leadership paradox in organization evolution: an executive team consensus-based exposition. Proc. Acad. Strateg. Manag. 15, 8-10.

Gioia, D. A., and Chittipeddi, K. (1991). Sensemaking and sensegiving in strategic change initiation. Strateg. Manag. J. 12, 433-448. doi: 10.1002/smj.4250120604

Gnyawali, D. R., Madhavan, R., He, J. Y., and Bengtsson, M. (2016). The competition-cooperation paradox in inter-firm relationships: a conceptual framework. Ind. Mark. Manag. 53, 7-18.

Hayes, T., and Usami, S. (2020). Factor score regression in connected measurement models containing cross-loadings. Struct. Equ. Model. Multi. J. 27, 942-951. doi: 10.1080/10705511.2020.1729160

Hocine, Z., and Zhang, J. (2014). Autonomy support: explaining the path from leadership to employee creative performance. Open J. Soc. Sci. 2, 417-423. doi: $10.4236 /$ jss.2014.26048

Ingram, A. E., Lewis, M. W., Barton, S., and Gartner, W. B. (2016). Paradoxes and Innovation in Family Firms: the Role of Paradoxical Thinking. Entrep. Theory Pract. 40, 161-176. doi: 10.1111/etap.12113

Ishaq, E., Bashir, S., and Khan, A. K. (2021). Paradoxical leader behaviors: leader personality and follower outcomes. Appl. Psychol. 70, 342-357.

Ji, L., Lee, A., and Guo, T. (2010). "The thinking styles of Chinese people," in The Handbook of Chinese Psychology, ed. M. H. Bond (Oxford: Oxford University Press), 155-167.

Kan, M. M., and Parry, K. W. (2004). Identifying paradox: a grounded theory of leadership in overcoming resistance to change. Leadersh. Q. 15, 467-491. doi: 10.1016/j.leaqua.2004.05.003

Knight, E., and Harvey, W. (2015). Managing exploration and exploitation paradoxes in creative organizations. Manag. Decis. 53, 809-827. doi: 10.3389/ fpsyg.2020.02041

Knight, E., and Paroutis, S. (2017). Becoming Salient: the TMT Leader's Role in Shaping the Interpretive Context of Paradoxical Tensions. Organ. Stud. 38, 403-432. doi: 10.1177/0170840616640844

Lewis, M. W. (2000). Exploring paradox: toward a more comprehensive guide. Acad. Manage. Rev. 25, 760-776. doi: 10.5465/amr.2000.3707712

Lewis, M. W., and Smith, W. K. (2014). Paradox as a metatheoretical perspective: sharpening the focus and widening the scope. J. Appl. Behav. Sci. 50, 127-149. doi: $10.1177 / 0021886314522322$

Lord, R. G., and Hall, R. J. (2005). Identity, deep structure and the development of leadership skill. Leadersh. Q. 16, 591-615. doi: 10.1016/j.leaqua.2005.06.003

Lüscher, L. S., and Lewis, M. W. (2008). Organizational change and managerial sensemaking: working through paradox. Acad. Manage. J. 51, 221-240. doi: 10.5465/amj.2008.31767217

Madjar, N., Greenberg, E., and Chen, Z. (2011). Factors for Radical Creativity, Incremental Creativity, and Routine, Noncreative Performance. J. Appl. Psychol. 96, 730-743. doi: $10.1037 / \mathrm{a} 0022416$

Mael, F. A., and Ashforth, B. E. (1992). Alumni and their alma mater: a partial test of the reformulated model of organizational identification. J. Organ. Behav. 13, 103-123.

Maitlis, S., and Christianson, M. (2014). Sensemaking in organizations: taking stock and moving forward. Acad. Manage. Ann. 8, 57-125.

Maitlis, S., and Sonenshein, S. (2010). Sensemaking in crisis and change: inspiration and insights from Weick (1988). J. Manage. Stud. 47, 551-580.

McArdle, S., Waters, L., Briscoe, J. P., and Hall, D. T. T. (2007). Employability during unemployment: adaptability, career identity and human and social capital. J. Vocat. Behav. 71, 247-264. doi: 10.1016/j.jvb.2007.06.003

Milosevic, I., Bass, A. E., and Combs, G. M. (2015). The Paradox of Knowledge Creation in a High-Reliability Organization: a Case Study. J. Manage. 44, 1174-1201. doi: 10.1177/0149206315599215 
Miron-Spektor, E., Gino, F., and Argote, L. (2011). Paradoxical frames and creative sparks: enhancing individual creativity through conflict and integration. Organ. Behav. Hum. Decis. Process. 116, 229-240. doi: 10.1016/j.obhdp.2011.03.006

Miron-Spektor, E., Keller, J., Smith, W. K., and Lewis, M. W. (2018). Microfoundations of organizational paradox: the problem is how we think about the problem. Acad. Manage. J. 61, 26-45. doi: 10.5465/amj.2016.0594

Motowidlo, S. J. (2000). Some basic issues related to contextual performance and organizational citizenship behavior in human resource management. Hum. Resour. Manag. Rev. 10, 115-126. doi: 10.1016/s1053-4822(99) 00042-x

Motowidlo, S. J., and Van Scotter, J. R. (1994). Evidence that task performance should be distinguished from contextual performance. J. Appl. Psychol. 79, 475-480. doi: 10.1037/0021-9010.79.4.475

Mumford, M. D., Friedrich, T. L., Caughron, J. J., and Byrne, C. L. (2007). Leader cognition in real-world settings: how do leaders think about crises?. Leadersh. Q. 18, 515-543. doi: 10.1016/j.leaqua.2007.09.002

Nag, R., Corley, K. G., and Gioia, D. A. (2007). The intersection of organizational identity, knowledge, and practice: attempting strategic change via knowledge grafting. Acad. Manage. J. 50, 821-847. doi: 10.5465/amj.2007.26279173

Pan, W., and Sun, L. (2018). A self-regulation model of zhong yong thinking and employee adaptive performance. Manage. Organ. Rev. 14, 135-159. doi: 10.1017/mor.2017.33

Ployhart, R. E., and Bliese, P. D. (2006). "Individual adaptability (I-ADAPT) theory: Conceptualizing the antecedents, consequences, and measurement of individual differences in adaptability," in Advances in human performance and cognitive engineering research, eds E. Salas, C. S. Burke, L. G. Pierce, and E. Salas (Amsterdam: Ellsevier), 3-39. doi: 10.1016/s1479-3601(05)06001-7

Pratt, M. G. (1998). "To be or not to be? Central questions in organizational identification," in Identity in organizations: Building theory through conversations, eds D. A. Whetten and P. C. Godfrey (Thousand Oaks: Sage), 171-207. doi: 10.4135/9781452231495.n6

Pratt, M. G. (2000). The good, the bad, and the ambivalent: managing identification among Amway distributors. Adm. Sci. Q. 45, 456-493. doi: 10.2307/2667106

Preacher, K. J., Rucker, D. D., and Hayes, A. F. (2007). Addressing moderated mediation hypotheses: theory, methods, and prescriptions. Multivariate Behav. Res. 42, 185-227. doi: 10.1080/00273170701341316

Ravasi, D., and Schultz, M. (2006). Responding to organizational identity threats: exploring the role of organizational culture. Acad. Manage. J. 49, 433-458. doi: 10.5465/amj.2006.21794663

Schad, J., Lewis, M. W., Raisch, S., and Smith, W. K. (2016). Paradox Research in Management Science: looking Back to Move Forward. Acad. Manage. Ann. 10, 5-64. doi: 10.1080/19416520.2016.1162422

Shao, Y., Nijstad, B. A., and Täuber, S. (2019). Creativity under workload pressure and integrative complexity: the double-edged sword of paradoxical leadership. Organ. Behav. Hum. Decis. Process. 155, 7-19. doi: 10.1016/j.obhdp.2019. 01.008

Smidts, A., Pruyn, A. T. H., and Van Riel, C. B. (2001). The impact of employee communication and perceived external prestige on organizational identification. Acad. Manage. J. 44, 1051-1062. doi: 10.5465/306 9448

Smith, K., and Berg, D. (1987). Paradoxes Of Group Life. San Francisco: Jossey-Bass.

Smith, W. K. (2015). Dynamic decision making: a model of senior leaders managing strategic paradoxes. Acad. Manag. J. 1015, 58-89.

Smith, W. K., Besharov, M. L., Wessels, A. K., and Chertok, M. (2012). A paradoxical leadership model for social entrepreneurs: challenges, leadership skills, and pedagogical tools for managing social and commercial demands. Acad. Manage. Learn. Educ. 11, 463-478. doi: 10.5465/amle.2011. 0021

Smith, W. K., and Lewis, M. W. (2011). Toward a theory of paradox: a dynamic equilibrium model of organizing. Acad. Manage. Rev. 36, 381-403. doi: 10. 5465/AMR.2011.59330958

Sonenshein, S. (2010). We're changing or are we? Untangling the role of progressive, regressive, and stability narratives during strategic change implementation. Acad. Manage. J. 53, 477-512. doi: 10.5465/amj.2010. 51467638

Sparr, J. L. (2018). Paradoxes in Organizational Change: the Crucial Role of Leaders' Sensegiving. J. Chang. Manage. 18, 162-180. doi: 10.1080/14697017.2018. 1446696

Uhl-Bien, M., and Arena, M. (2018). Leadership for organizational adaptability: a theoretical synthesis and interative framework. Leadersh. Q. 29, 89-104. doi: 10.1016/j.leaqua.2017.12.009

Van der Heijde, C. M., and Van der Heijden, B. I. J. M. (2006). A competence-based and multidimensional operationalization and measurement of employability. Hum. Resour. Manage. 45, 449-476. doi: 10.1002/hrm.20119

Van der Heijden, B. I. J. M., Notelaers, G., Peters, P., Stoffers, J. M. M., De Lange, A. H., Froehlich, D. E., et al. (2018). Development and validation of the shortform employability five-factor instrument. J. Vocat. Behav. 106, 236-248. doi: 10.1016/j.jvb.2018.02.003

van Knippenberg, D., Van Knippenberg, B., De Cremer, D., and Hogg, M. A. (2004). Leadership, self, and identity: a review and research agenda. Leadersh. Q. 15, 825-856. doi: 10.1007/s40279-015-0345-4

Vince, R., and Broussine, M. (1996). Paradox, defense and attachment: accessing and working with emotions and relations underlying organizational change. Organ. Stud. 17, 1-21. doi: 10.1177/017084069601700101

Wang, H. J., Demerouti, E., and Blanc, P. L. (2017). Transformational leadership, adaptability, and job crafting: the moderating role of organizational identification. J. Vocat. Behav. 100, 185-195. doi: 10.1016/j.jvb.2017.03.009

Weick, K. E. (1993). The collapse of sensemaking in organizations: the Mann Gulch disaster. Adm. Sci. Q. 38, 628-652. doi: 10.2307/2393339

Weick, K. E. (1995). Sensemaking in Organizations. Thousand Oaks: sage Publications.

Weick, K. E., Sutcliffe, K. M., and Obstfeld, D. (2005). Organizing and the process of sensemaking. Organ. Sci. 16, 409-421.

Wu, C. H., and Lin, Y. C. (2005). Development of a zhong-yong thinking style scale. Indigenous Psychol. Res. Chin. Soc. 24, 247-300.

Yang, C. F. (2010). Multiplicity of Zhong Yong Studies. Indigenous Psychol. Res. Chin. Soc. 34, 3-96.

Yang, Y., Li, Z. Q., Liang, L., and Zhang, X. (2021). Why and when paradoxical leader behavior impact employee creativity: thriving at work and psychological safety. Curr. Psychol. 40, 1911-1922. doi: 10.1007/s12144-018-0095-1

Yao, X. Q. Yang, Dong, N., and Wang, L. (2010). Moderating Effect of Zhong Yong on the Relationship between Creativity and Innovation behavior. Asian J.Soc. Psychol. 13, 53-57. doi: 10.1037/apl0000397

Zhang, M. J., Zhang, Y., and Law, K. S. (2021). Paradoxical leadership and innovation in work team: the multilevel mediating role of ambidexterity and leader vision as a boundary condition. Acad. Manage. J. (in press)

Zhang, Y., Waldman, D. A., Han, Y. L., and Li, X. B. (2015). Paradoxical leader behaviors in people management: antecedents and consequences. Acad. Manage. J. 58, 538-566. doi: 10.1080/14616730500365944

Conflict of Interest: The authors declare that the research was conducted in the absence of any commercial or financial relationships that could be construed as a potential conflict of interest.

Publisher's Note: All claims expressed in this article are solely those of the authors and do not necessarily represent those of their affiliated organizations, or those of the publisher, the editors and the reviewers. Any product that may be evaluated in this article, or claim that may be made by its manufacturer, is not guaranteed or endorsed by the publisher.

Copyright (c) 2021 Zhang, Liao, Liao and Zheng. This is an open-access article distributed under the terms of the Creative Commons Attribution License (CC BY). The use, distribution or reproduction in other forums is permitted, provided the original author(s) and the copyright owner(s) are credited and that the original publication in this journal is cited, in accordance with accepted academic practice. No use, distribution or reproduction is permitted which does not comply with these terms. 